\title{
Key Competencies of Physics Teachers
}

\author{
Tingting Liu $^{1} \&$ Haibin Sun ${ }^{1}$ \\ ${ }^{1}$ College of Physics and Electronic Engineering, Taishan University, Tai'an City, China \\ Correspondence: Tingting Liu, College of Physics and Electronic Engineering, Taishan University, Tai'an City, \\ 271000, China. E-mail: liuttphy@tsu.edu.cn
}

Received: October 25, 2020

Accepted: November 13, $2020 \quad$ Online Published: December 1, 2020

doi:10.5539/hes.v11n1p28

URL: https://doi.org/10.5539/hes.v11n1p28

\begin{abstract}
In China, the main goal of basic education curriculum reform is to develop students' key competencies. The physics teaching directed by key competencies would not only aim at the memory and reappearance of physics knowledge but also the application of physics knowledge and methods. As teachers who guide students' learning and implement teaching activities, the improvement and development of their key competencies plays an important role in the development of students. The key competencies of physics teachers consist of physics literacy, education and teaching literacy, scientific literacy, humanistic literacy, information literacy, and life-long learning ability.
\end{abstract}

Keywords: key competencies, physics teacher, teacher professional development, teaching reform

\section{Introduction}

Key Competencies play a basic role as the first guidelines for educators in handling an increasingly diverse and interconnected surrounding world and could be broadened to formulate a kind of "statements of action" (Dębowska \& Greczyło, 2017). Key competencies education reform has been a topic of multiple international organizations, countries and areas for the past few decades, and it even has been a key point of some countries and areas to undertake education reform and curriculum reform. This is the development trend of international education reform in the future.

The Organization for Economic Cooperation and Development (OECD) is the first international organization to carry out research on Key Competencies, and the main reason for the proposal of the key competency is to tackle and solve the following problems: what kinds of abilities that people should have for better living in future society; what abilities people need to have when looking for a job and to be competent for the requirements of the job and what qualities people need to improve to keep up with changing technology. A study undertaken under the OECD's auspices, definition and selection of competencies identifies nine key competencies under three broad categorizations: (1) acting autonomously, (2) using tools interactively and (3) functioning in socially heterogeneous groups (Takayama, 2013). The European Union recommends eight key competencies for its member states as a reference framework to push education reform (Blaskova, Blasko, Matuska, \& Rosak-Szyrocka, 2015; Pirrie \& Thoutenhoofd, 2013). The eight key competencies include the ability to communicate in the native language, the ability to communicate in foreign languages, mathematical and technological literacy, digital literacy, learning to learn, social and civic literacy, initiative and innovation awareness, cultural awareness and expression. Each literacy is described in detail in the three dimensions of knowledge, skills and attitude (Jones, 2017).

In 2011, the Australian federal government released the Australian Professional Standards for Teachers (APST). The APST describes seven standards, organized under three domains, as follows: (1) Professional knowledge. Know students and how they learn; know the content and how to teach it. (2) Professional practice. Plan for and implement effective teaching and learning; create and maintain supportive and safe learning environment; assess, provide feedback, and report on student learning. (3) Professional engagement. Engage in professional learning; and engage professionally with colleagues, parents/carers, and the community.

In March 2014, Opinions on Comprehensively Deepening the Curriculum Reform and Implementing the Fundamental Task of Cultivating Morality and Cultivating People released by the Chinese Ministry of Education makes the building of students' key competencies as the key to education reform. On September 13, 2016, the study result of the key competencies of Chinese students' development was officially released, and it clearly 
states that the development of key competencies in students should be the guidance of all subjects (Group, 2016). The development of key competencies of Chinese students should be cored with "to be an all-ground developed person," and they are divided into cultural foundation, independent development and social participation. The comprehensive performance includes humanities, scientific spirit, learning to learn, healthy life, responsibility, practice and innovation. Key competencies restrict the objectives, content and form of school education to a great extent. In essence, focusing on the key competencies of students means paying attention to a basic education problem: What kind of person should be cultivated? At the end of 2017, the education ministry printed a new curriculum plan for senior high school and a curriculum standard of 14 subjects such as Chinese that refines the key competencies of all subjects. The curriculum standards of all subjects further select the subject's content to urge the progress toward the subject key competency.

Teachers are the most dynamic factor and main implementers in school education. This factor directly affects and determines students' development. Hence, teachers are a key point in the success of basic education reform. The suggestion of key competencies is a challenge for professional development of teachers, and it is also an opportunity and direction. It could bring out stress and motivation for teachers' career education; and could improve the urgency of teachers' professional development. Teaching is a combination of teaching and learning, so it should be completed in the learning community formed by teachers and students. The key competencies propose a new requirement for the growth of students, and there is also change in the professional literacy of teachers in the community. The educational concept, professional knowledge and teaching technology teachers should have should be an all-around improvement strategy to satisfy the diversified demand of students in the time of education reform. In the reform of the basic education curriculum, the implementation of teaching and learning could not work without teachers. As students' learning guides, their own professional growth implementers, and curriculum and teaching practice researchers and reflectors, teachers' key competencies promotion and development mean so much to the all-round development of students (Pingxia, 2018).

The development key competencies framework for Chinese students has been proposed and the new curriculum standard has been revised, but the key competency and ability standard of teachers in our country have not been in the schedule, and there is still no unified standard of teachers' key competencies. There is also lack of systemic interpretation of the concept and structure of the key competencies of teachers. Based on Guangming Wang et al. (Guangming, Qianping, Yongjian, \& Libao, 2019), the key competencies of teachers should include moral cultivation, educational spirit, and cultural cultivation, and the core ability of teachers should be contained in their education and teaching ability, learning and innovation ability, communication and cooperation ability. Shuang Feng (Shuang, 2016) holds the opinion that physics teachers should be trained from the aspects of the formation of physics knowledge, experimental operation and guidance, establishment of thinking methods, understanding of the nature of the subject and social responsibility to improve the subject key competencies of physics teachers.

Based on the key competencies theory and the key competency framework of physics, we clarify the key competencies structure that middle school physics teachers should have from the perspective of teacher professional development.

\section{Key Competencies of Physics}

The physics teaching directed by key competencies would not only aim at the memory and reappearance of physics knowledge but also the application of physics knowledge and methods, so as to push the development of key abilities and essential character of middle school students (Dębowska \& Greczyło, 2017). Here is the definition of key competencies of physics in Curriculum Standard of Physics in Senior High School: The key competencies of physics are the collective performance of educational value of physics, and the critical ability and necessary style students should form gradually in the process of receiving physics education to fit the lifelong development and social demand, and it is the important composition of students' scientific literacy. As for the connotation and the compositions of the key competencies of physics, four aspects are defined in the Curriculum Standard of Physics in Senior High School: physics concept, scientific thinking, scientific exploration, and scientific attitude and responsibility.

The concept of physics is the basic understanding of matter, motion and interaction, energy and so on formed from the perspective of physics in the concept of physics; it is the refined and sublimated physics concepts and laws in the mind; and it is the foundation to explain the natural atmosphere and to solve actual problems from the aspect of physics. Physics opinion mainly consists of material concepts, movement and interaction concepts, energy concepts and other elements.

Scientific thinking is a way of understanding the essential attributes, internal laws and mutual relations of 
objective things from the perspective of physics; it is an abstract conclusion process to build up a physics model based on experimental facts; it is the specific application of analysis and synthesis, reasoning, demonstration and other methods in the scientific filed. It is the ability and character to raise doubts and critique different opinions and conclusions based on factual evidence and scientific reasoning, and there is verification and correction to propose creational understanding. Scientific thinking is formed by model construction, scientific reasoning, scientific demonstration, query and innovation.

Scientific exploration refers to the ability to propose a physics problem based on observations and experiments, form conjectures and hypotheses, design experiment and stipulate schemes, acquire and process information, gain conclusions based on evidence and make interpretations, and participate in exchange, evaluation and reflection on the process and results of discipline inquiry. Scientific exploration mainly comprises of the question, evidence, explanation, exchange, and other factors.

Scientific attitude and responsibility refer to the responsibility to gradually form an intrinsic motivation to explore nature, a scientific attitude of preciseness, seriousness, seeking truth from facts and perseverance, and a sense of responsibility to abide by moral norms and to protect the environment and promote sustainable development based on the understanding of the relationship among science, technology, society and the environment. Scientific attitude and responsibility mainly includes science, scientific attitude, social responsibility and other factors.

Professor Hongjun Xing rebuilt the key competencies of physics by integrating the general key competencies and the subject features of physics (Hongjun, 2018). He believes that the key competencies of physics should be physics knowledge and physics methods, physics thinking and physics skills, physics concepts, scientific spirit, and humanistic spirit. There are two dimensions at every level.

Physics knowledge. The performance of physics knowledge is the concepts and laws of physics. The knowledge and methods are mutually connected to form the knowledge structure of students' study contents. For fundamentality, implant ability and teach ability, physics knowledge and physics methods have become the basis of the key competencies of physics.

Physics thinking and physics skills go through the whole process of study of learners, and thinking ability is also the core of study ability and the premise of accepting knowledge, finding knowledge and building knowledge. The observation of the physics atmosphere, measurement of experimental data, abstraction of physics models, forming of physics concepts, buildup of physics theories, and solving of physics problems could not work without physics thinking. Learners process and handle the study objects in their minds through thinking of analysis, synthesis, abstraction, generalization, comparison, judgment, hypothesis, reasoning, intuition, and imagination, so as to build up physics knowledge. Skill development is a complicated system in which individuals form knowledge of intellectual and physics movements through practice with existing knowledge and experience, including mental skills and motor skills.

Physics thinking and physics concepts refer to a deep understanding of the essence of physics formed by the physics community's further generalization of physics knowledge and methods in the development of physics. Physics concepts are a concentration of important physics thinking because only an understanding representing the most basic laws of physics could be called physics concepts.

Scientific spirit and humanistic spirit emerge along with modern science. Based on the inheritance of human thought, the gradual development of scientific ideas and the accumulation of scientific tradition are the integration of values and norms contained in scientific culture. Scientific spirit contains reasonable query, independent thinking, a rigorous scientific attitude, and a lofty scientific ideal. Humanistic spirit is a universal human self-care. It shows the maintenance, pursuit, and concern for human dignity, value, and destiny, and it highly values various spiritual and cultural phenomena left over by human beings. It is a confirmation and shaping of an all-around ideal personality.

\section{Key Competencies of Physics Teachers}

Key competencies of physics teachers refer to the key abilities and necessary literacy of physics teachers that have been formed in the process of teaching to adjust to the comprehensive development of students and the realization of self-development. The key competencies of physics teachers in middle schools mainly consist of physics literacy, education and teaching literacy, scientific literacy, humanistic literacy, information literacy, and life-long learning ability.

\subsection{Physics Literacy}

Physics literacy refers to the collection of all literacy gradually formed in the education and teaching practice and 
the self-study process after a physics teacher accepts systemic higher physics education, which could effectively guide the education and teaching activity of physics and profoundly affect students' physical and mental development. Subject literacy is the foundation of the key competencies of physics teachers. The physics literacy of physics teachers mainly includes physics knowledge, physics experiment knowledge and skills, physics thinking and physics thought, and methodology, and it is the comprehensive performance of theoretical literacy, methodological literacy, practical literacy, and character literacy. Physics knowledge comprises physics facts, physics concepts, physics laws, and physics theories (Haibin, 2019). The knowledge of physics methodology should be based on conventional methods (observation and experiment, analysis and synthesis, comparison and classification, induction and deduction, analogy, idealization, hypothesis, mathematical method, cybernetics, system theory, information theory, synergism, etc.) and unconventional methods (intuition and inspiration, opportunity, scientific imagination and conjecture, physics aesthetics, mistakes and fallacies, etc.).

\subsection{Education and Teaching Literacy}

The education and teaching literacy of physics teachers mainly includes literacy of education theory, ability of education teaching, and ability of teaching study. The literacy of education theory consists of education and teaching knowledge, psychological knowledge, and physics pedagogy knowledge, which should be a theoretical basis for an excellent teacher. The ability to teach education should be basic teaching skills, teaching design ability, teaching ability in accordance with aptitude, experimental operation ability, blackboard writing and painting ability, language expression ability, etc. Physics teachers must be equipped with consolidated teaching foundations to effectively control the class. They should adopt effective teaching methods and strategies to improve the teaching literacy of class so as to push the development of students in academic achievement. Simultaneously, teaching studies should be carried out in combination with teaching practice to fix problems encountered in physics teaching. Physics teachers should give up the passive habit of relying on experience transmission and educational theory researchers to provide new theoretical achievements, and they should actively change from being simple educational practitioners to thinking and research-oriented educational practitioners.

\subsection{Scientific Literacy}

Physics education would not only help students acquire knowledge and skills but also obtain the edification and cultivation of scientific literacy. Miller (Gu, Wang, \& Lin, 2019) defined scientific literacy from three dimensions: (1) understanding of the science norms and methods, (2) understanding core terms and concepts in science, and (3) understanding the impact of science and technology on society. As a performer of physics education, physics teachers must have good scientific literacy. Scientific literacy includes scientific knowledge, scientific methods, scientific spirit (attitude and emotion), and scientific values. Scientific spirit is the core of scientific literacy. The development of the scientific literacy of physics teachers shall be based on the mastering and accumulation of scientific knowledge and skills.

\subsection{Humanistic Literacy}

There is a close relationship between scientific literacy and humanistic literacy. Humanistic literacy is also a critical component of the key competencies of physics teachers. Good humanistic literacy is a catalyst to improve the level of teachers' professional development. The humanistic literacy of physics teachers should be humanistic knowledge, spirit, and behavior. Besides natural and scientific knowledge, physics teachers should also have sufficient humanistic knowledge reserves, such as knowledge of literature, history, philosophy, and aesthetics. The key performance of humanistic spirit is to love the education career and to comply with professional ethics, care for students, respect for students, and a pleasant personality. The humanistic behavior of teachers in teaching is as follows: self-discipline, setting as a demonstration, paying attention to teaching by example, respecting students' differences, and focusing on the cultivation of students' nonintellectual factors. Hence, physics teachers could nurture students' thirst for knowledge with profound knowledge and self-restraint so as to stimulate students' enthusiasm for exploration and shaping their own good image. Hence, they could cultivate students' scientific literacy and have an effective role in humanistic literacy at the same time so that the key competencies of students could be well developed.

\subsection{Information Literacy}

Information literacy is highly important for physics teachers' online teaching and electronic learning (e-learning). For physics teachers, information literacy is not only the ability to use information technology, but also the ability to find, evaluate, analyze, integrate, communicate, and use information to teaching. Information-literate physics teachers have sensitive conscious of information resources in daily life, reinforce technology skills and integrate information technology with their instruction (Sun \& Liu, 2009). In response to COVID-19, many 
countries have applied strict social distancing measures and a lockdown policy. The pandemic has had a tremendous impact on schools, students and teachers. E-learning has been considered the best possible approach to continue the teaching and learning process during the pandemic (Mailizar, Almanthari, Maulina, \& Bruce, 2020). As faculty members worldwide face online teaching, they must consider how to maximize value for their students (Gewin, 2020). Information literacy enables physics teachers to master content and extend their investigations, become more self-directed, and assume greater control over their own teaching and students' learning.

\subsection{Lifelong Learning Ability}

Lifelong learning has a key role to play for human development and social transformation (Hanemann, 2019). Lifelong learning ability is the ability to integrate knowledge, skills, and attitudes and develop continuously in order to adapt to social changes. It is portable and has diversified functions. Physics teachers must keep pace with time to keep self-learning so as to stay at the cutting-edge development of physics. Teachers should focus on the cross integration of physics knowledge and the frontier of modern science and technology and their integration among subjects. They should build up a physics knowledge structure with modern charm. The physics course should have features of time, striving to achieve the dynamic linkage of real society so as to help students understand real society with the physics knowledge they have learned and explain physics science according to the perception of social reality; hence, students could master physics knowledge in a more comprehensive way.

\section{Conclusion}

The key competencies of physics teachers are the guarantee of teachers' professional development. In the key competency framework system of physics teachers, subject literacy and education teaching literacy are the literacy exclusive to teachers, and it also shows the professional nature of the career. As knowledge owners, disseminators, and representatives of social mainstream culture, teachers should have higher-level subject literacy and should not only master the knowledge of the subject systematically but also understand interdisciplinary knowledge.

\section{Acknowledgements}

This work was supported by the Teacher Education Research Special Project of Taishan University (JY-02-202022) and the Teaching Reform Project of Taishan University (201836).

\section{References}

Blaskova, M., Blasko, R., Matuska, E., \& Rosak-Szyrocka, J. (2015). Development of Key Competences of University Teachers and Managers. Procedia - Social and Behavioral Sciences, 182, 187-196. https://doi.org/10.1016/j.sbspro.2015.04.755

Dębowska, E., \& Greczyło, T. (2017). Role of Key Competencies in Physics Teaching and Learning. In T. Greczyło \& E. Dębowska (Eds.), Key Competencies in Physics Teaching and Learning (pp. 3-9). Springer Proceedings in Physics, Springer, Cham. https://doi.org/10.1007/978-3-319-44887-9_1

Gewin, V. (2020). Five tips for moving teaching online as COVID-19 takes hold. Nature, 580, 295-296. https://doi.org/10.1038/d41586-020-00896-7

Gu, X., Wang, C. \& Lin, L. (2019). Examining Scientific Literacy through New Media. EURASIA Journal of Mathematics, Science and Technology Education, 15(12). https://doi.org/10.29333/ejmste/109948

Guangming, W., Qianping, W., Yongjian, Z., \& Libao, W. (2019). The Re-exploration of the Structure System of Teachers' Key Competencies and Abilities. Education Sciences in China, 2(4), 59-73. Retrieved from https://www.pep.com.cn/bks/zgjykxzyw/jctj/201908/t20190819_1944369.shtml

Haibin, S. (2019). Teacher Knowledge Structure of Physics Teachers. International Journal of Engineering Applied Sciences and Technology, 4(3), 55-61. https://doi.org/10.33564/IJEAST.2019.v04i03.007

Haibin, S., \& Tingting, L. (2009). Cultivation of Science Teachers' Information Literacy in China. International Education Studies, 2(3), 147-150. https://doi.org/10.5539/ies.v2n3p147

Hanemann, U. (2019). Examining the application of the lifelong learning principle to the literacy target in the fourth Sustainable Development Goal (SDG 4). International Review of Education, 65(2), 251-275. https://doi.org/10.1007/s11159-019-09771-8

Hongjun, X. (2018). Key compentences of Physics: Perspective, Discussion and Reconstruction. Educational 
Science Research, 11, 5-14. Retrieved from https://mp.weixin.qq.com/s/2azOfp0WwAj0RLz6j12KPg

Jones, G. (2017). Competence and Understanding - A Personal Perspective. In T. Greczyło \& E. Dębowska (Eds.), Key Competencies in Physics Teaching and Learning. Springer Proceedings in Physics (pp. 11-24). Springer, Cham. https://doi.org/10.1007/978-3-319-44887-9_2

Mailizar, A. A., Maulina, S., \& Bruce, S. (2020). Secondary School Mathematics Teachers' Views on E-learning Implementation Barriers during the COVID-19 Pandemic: The Case of Indonesia. Eurasia Journal of Mathematics, Science and Technology Education, 16(7), em1860. https://doi.org/10.29333/ejmste/8240

Key Compentenceis Research Group. (2016). Developing Key Compentencies for Chinese Students. Journal of The Chinese Society of Education, 10, 1-3. https://www.jcse.com.cn/CN/Y2016/V0/I10/1

Pingxia, S. (2018). Exploration of Teacher Professional Development Paths Based on Students' Key Compentencies. Journal of Educational Development, 8, 63-67. https://10.16215/j.cnki.cn44-1371/g4.2018.08.012

Pirrie, A., \& Thoutenhoofd, E. D. (2013). Learning to learn in the European Reference Framework for lifelong learning. Oxford Review of Education, 39(5), 609-626. https://doi.org/10.1080/03054985.2013.840280

Shuang, F. (2016). Enhance the Development of Middle School Physics Teachers based on Key Compentencies. Physics Teaching In Middle School, 45(10), 82-83. https://doi.org/mall.cnki.net/magazine/Article/ZXWL201610050.htm

Takayama, K. (2013). OECD, 'Key competencies' and the new challenges of educational inequality. Journal of Curriculum Studies, 45(1), 67-80. https://doi.org/10.1080/00220272.2012.755711

\section{Copyrights}

Copyright for this article is retained by the author(s), with first publication rights granted to the journal.

This is an open-access article distributed under the terms and conditions of the Creative Commons Attribution license (http://creativecommons.org/licenses/by/4.0/). 